Original Artikel

Spizaetus: Jurnal Biologi dan Pendidikan Biologi

Volume 2, Nomor 2, Juni 2021

pISSN: 2716-151X

eISSN: 2722-869X

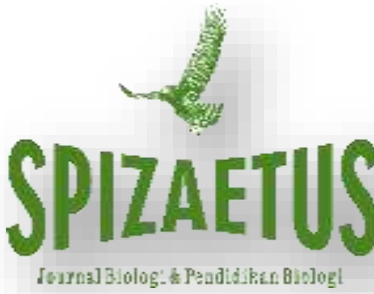

\title{
Etnobotani Tanaman Cabai Merah Keriting (Capsicum Annum L.) Di Desa Waiwuring, Kecamatan Witihama Kabupaten Flores Timur
}

\author{
Nurul Imaniyah Ahmad ${ }^{1}$, Yohanes Nong Bunga ${ }^{1}$, Yohanes Bare ${ }^{1 *}$ \\ ${ }^{1}$ Program Studi Pendidikan Biologi, Fakultas Keguruan dan Ilmu Pendidikan, \\ Universitas Nusa Nipa Indonesia, Sikka, Indonesia, 86111 \\ Email*: bareyohanes@gmail.com
}

\begin{abstract}
ABSTRAK
Cabai merah keriting (Capsicum annum L.) merupakan salah satu komoditas sayuran yang banyak dibudidayakan oleh petani Indonesia karena memiliki harga jual yang tinggi dan memiliki beberapa manfaat kesehatan. Selain pemanfaatan sebagai zat adiktif dalam pengobatan tradisional cabai merah keriting (Capsicum annum L.), juga digunakan untuk pengobatan batuk, sakit gigi, radang tenggorokan, parasite, rematik, dan juga digunakan sebagai antiseptik, kontrairitasi, nafsumakan. Penelitian ini memiliki tujuan untuk menganalisis pengetahuan masyarakat terhadap etnobotani tanaman cabai merah keriting (Capsicum annum L.) di Desa Waiwuring, Kecamatan Witihama, Kabupaten Flores Timur. Metode Yang digunakan adalah metode wawancara pengetahuan tradisional masyarakat desa Waiwuring. Hasil penelitian menunjukkan bahwa cabai merah keriting (Capsicum annum L.) dimanfaatkan sebagai obat tradisional. Beberapa cara pengolahan sebagai obat diantaranya diambil beberapa helai daun cabai merah keriting, dicuci, dihaluskan dan kemudian ditempelkan pada bagian yang terkena bisul. Sedangkan untuk pengobatan sakit gigi dengan cara diambil biji cabai merah keriting, kemudian dibakar, lalu di uapkan menggunakan bambu yang berukuran sangat kecil. Setelah itu, asap cabai yang berada di dalam bambu di tiup dan di saring menggunakankapas, kemudian dari kapas tersebut di simpan dibagian gigi yang sakit (berlubang).
\end{abstract}

Kata Kunci: cabai merah keriting, desa waiwuring, etnobotani, pengobatan tradisional

\section{PENDAHULUAN}

Cabai (Capsicum annum L.) merupakan salah satu jenis buah yang sering di manfaatkan sebagai sayur karena mempunyai nilai ekonomi yang tinggi. Cabai (Capsicum annum L.) dikonsumsi dalam bentuk segar maupun olahan. Pada awalnya, cabai dikonsumsi untuk memenuhi kebutuhan rumah tangga yaitu sebagai bahan pelengkap makanan atau sering dikenal dengan rempah atau bumbu dapur. Seiring dengan kebutuhan manusia dan teknologi yang berkembang saat ini, cabai juga digunakan sebagai bahan baku industri untuk obat-obatan, kosmetik, zat warna, dan penggunaan lainnya (Fitriani dkk., 2013). 
Produksi Cabai (Capsicum annum L.) di Provinsi NTT dari tahun ke tahun mengalami fluktuatif atau naik turun. Berdasarkan data BPS (2019) Kabupaten Flores Timur, dari tahun 2017 sampai 2019 produksi tanaman cabai mengalami peningkatan yaitu di tahun 2017 produksi cabai mencapai 25\%, pada tahun 2018 produksi cabai mencapai 27,25\% dan pada tahun 2019 produksi cabai mencapai 27,31\%. Produksi cabai (Capsicum annum L.) ini sejalan dengan pola konsumsi masyarakat yang ada di Kabupaten Flores Timur.

Masyarakat Kabupaten Flores Timur sering menggunakan cabai (Capsicum annum L.) sebagai bumbu dapur. Selain pemanfaatan sebagai bumbu dapur, masyarakat di Kabupaten Flores Timur juga menggunakan cabai sebagai obat tradisional yang mampu menyembuhkan penyakit. Penggunaan sebagai obat memiliki keunikan untuk setiap wilayah di Kabupaten Flores Timur berdasarkan adat istiadat yang berlaku. Hasil penelitian pada masyarakat Desa Waiwuring Kecamatan Witihama Kabupaten Flores Timur, menggunakan bagian dari daun cabai sebagai obat sakit gigi dengan cara diambil beberapa helai daun segar, lalu dicuci bersih kemudian ditumbuk dan ditempelkan pada bagian pipi dekat gigi yang sakit. Pengetahuan lokal masyarakat setempat perlu untuk di dokumentasikan agar tidak hilang pada zaman modern, karena hanya diwariskan pada keturunan tertentu.

Pengetahuan lokal tersebut belum teruji secara ilmiah karena masyarakat hanya mempercayai pada hasil yang diperoleh. Pengalaman masyarakat perlu di uji secara ilmiah untuk mengetahui potensi farmakologi dari tanaman cabai. Hasil studi literatur menunjukkan tanaman cabai mengandung berbagai macam bioaktif kimia. Studi literatur tanaman cabai menunjukkan kandungan utama Capsaicinoid pada cabai adalah capsaicin, diikuti oleh dihydrocapsaicin, homocapsaicin, nonivamide, nordihydrocapsaicin, homodihydrocapsaicin, dan nornodihydrocapsaicin yang dapat digunakan untuk mengobati penyakit seperti pegal-pegal, rematik, batuk, dan infeksi saluran cerna (Izzati 2018). Jenis sakit yang diobati menurut kajian referensi merupakan kondisi inflamasi di dalam tubuh manusia (Bare 2021; Bare et al. 2019, 2020; Bhadoriya 2012). Tujuan Penelitian ini adalah Menganalisis pengetahuan masyarakat terhadap etnobotani tanaman cabai merah keriting (Capsicum annum L.) di Desa Waiwuring, Kecamatan Witihama, Kabupaten Flores Timur. 


\section{METODOLOGI PENELITIAN}

Penelitian ini tergolong dalam deskriptif eksplorasi. Metode dalam etnobotani terdiri atas wawancara terstruktur (structured interview) disertai keterlibatan aktif peneliti kepada masyarakat (Participatory Ethnobotanical Apprasial) diwilayah Kabupaten Flores Timur khusunya di Desa Waiwuring. Sampel penelitian ini adalah informan kunci (key informant) sebanyak 3 orang dan non informan kunci sebanyak 7 orang dari Desa Waiwuring, Kecamatan Witihama, Kabupaten Flores Timur.

Prosedur Penelitian

1. Studi Pendahuluan

Studi pendahuluan dilakukan untuk mengetahui desa yang akan dijadikan sebagai lokasi penelitian dan penentuan informan kunci atau key informan. Informan kunci merupakan orang yang lebih memahami tentang tumbuhan obat. Untuk pemilihan lokasi penelitian terlebih dahulu harus mengetahui bahwa masyarakat desa tersebut masih menggunakan tumbuhan sebagai obat tradisional.

2. Survey Etnobotani

Survey etnobotani meliputi survey lapangan, pengambilan data dan wawancara. Untuk mengetahui kearifan lokal masyarakat di Desa Waiwuring, Kecamatan Witihama terhadap tumbuhan obat tradisional, maka dilakukan wawancara dengan penduduk setempat baik berupa nama lokal tumbuhan, bagian atau organ tumbuhan yang digunakan, cara perolehan serta cara pemanfaatan.

3. Pengumpulan Data

Pengumpulan data tentang etnobotani tumbuhan cabai yang berpotensi sebagai obat penyakit oleh masyarakat Desa Waiwuring, dilakukan dengan menggunakan teknik wawancara terstruktur yang berpedoman pada daftar pertanyaan seperti: nama lokal tumbuhan, bagian yang dimanfaatkan, cara perolehan tumbuhan serta cara pemanfaaatan. Bahasa yang digunakan dalam wawancara adalah bahasa Lamaholot, bahasa Bajo dan bahasa Indonesia disesuaikan dengan kemampuan responden.

4. Teknik Analisis Data

Analisis data dalam penelitian ini menggunakan teknis analisis deskriptif kualitatif dan kuantitatif. Analisis data berupa analisis isi (content analysis) berdasarkan data pengetahuan responden terhadap tumbuhan sebagai obat. Data kualitatif didapat dari hasil wawancara masyarakat, sedangkan data kuantitatif berupa persentase penggunaan tumbuhan obat berupa organ tumbuhan, sumber perolehan tumbuhan dan 
tingkat penggunaan jenis tumbuhan. Identifikasi tumbuhan dicocokkan dengan literatur yang mendukung.

\section{HASIL DAN PEMBAHASAN}

\section{Gambaran Umum Desa Waiwuring, Kecamatan Witihama, Kabupaten Flores} Timur

Desa Waiwuring merupakan salah satu desa dari 16 desa yang ada di Kecamatan Witihama yang dihuni oleh Suku Bajo dan terletak dibibir pantai Selat Boleng yang indah dengan jarak tempuh dari kota kecamatan Witihama 5 km.

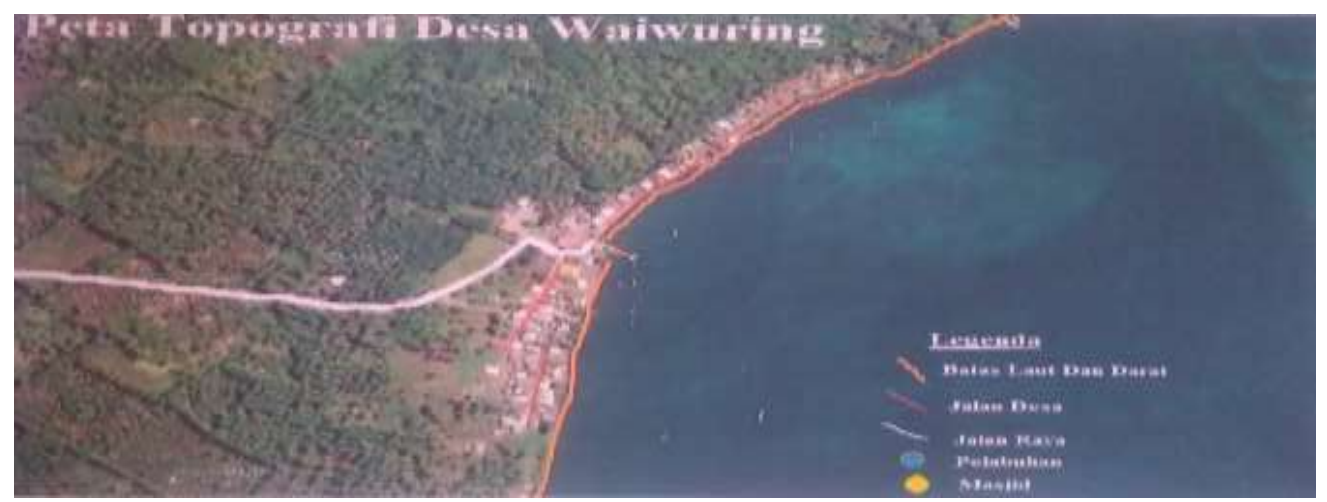

Gambar 1. Peta Topografi Desa Waiwuring (sumber: Profil Desa)

Desa Waiwuring memiliki 425 jiwa. Secara geografis, Desa Waiwuring terletak dibibir pantai yang memiliki luas $350 \mathrm{Ha}$ dan batas, yaitu Utara berbatasan dengan Desa Pledo, Timur berbatasan dengan Selat Boleng, Selatan berbatasan dengan Desa Riangduli, Barat berbatasan dengan Desa Oringbele. Desa Waiwuring memiliki 1 unit polindes yang terletak di dusun 1 Mehin Koi. Jarak antar dusun ke polindes 300 meter. Polindes yang tersedia cukup memadai, karena memiliki 4 tenaga kesehatan diantaranya 2 bidan, 1 perawat, dan 1 tenaga kesehatan lingkungan (kesling). Umumnya masyarakat berobat ke polindes, namun selama proses pengobatan tidak sembuh maka masyarakat memilih untuk pergi ke dukun/tabib. Alasan lain masyarakat memilih pergi ke tabib/dukun, karena keadaan ekonomi sebagian masyarakat yang kurang mampu.

2. Pengetahuan Tanaman Cabai Merah Keriting (Capsicum annum L.) Masyarakat Desa Waiwuring

Masyarakat Desa Waiwuring menyebut cabai dalam Bahasa lokal dengan sebutan cabi/sili. Masyarakat Desa Waiwuring memiliki pengetahuan dalam mengolah 
keanekaragaman sumber daya alam di lingkungan sekitarnya. Salah satu pengolahan sumberdaya alam tersebut adalah penggunaan tanaman cabai merah keriting (Capsicum annum L.) sebagai bahan tambahan pangan. Pemanfaatan lainnya dari tanaman cabai ini adalah sebagai obat tradisional yang mampu menyembuhkan berbagai macam penyakit seperti bisul dan sakit gigi.

Tabel 1. Perekam Data Hasil Penelitian Cabai Merah Keriting (Capsicum annum L.)

\begin{tabular}{|c|c|c|c|c|}
\hline No. & Informan & Nama Lokal & $\begin{array}{c}\text { Organ Yang } \\
\text { Digunakan dan } \\
\text { Cara Perolehan }\end{array}$ & Cara Pemanfaatan \\
\hline 1. & 1 & Cabi/Sili & $\begin{array}{c}\text { Diambil biji lombok } \\
\text { dari buah lombok }\end{array}$ & $\begin{array}{l}\text { Untuk sakit gigi: diambil } \\
\text { biji lombok dari buah } \\
\text { buah lombok kemudian } \\
\text { dibakar, lalu di aspkan } \\
\text { menggunakan bambu } \\
\text { yang berukuran sangat } \\
\text { kecil. Setelah itu, asap } \\
\text { cabai yang berada di } \\
\text { dalam bambu di tampung } \\
\text { pada kapas, kemudian dari } \\
\text { kapas tersebut di } \\
\text { masukkan dibagian gigi } \\
\text { yang sakit (berlubang). } \\
\text { Untuk bisul: diambil } \\
\text { beberapa helai daun } \\
\text { lombok, dicuci kemudian } \\
\text { dihaluskan, dan di } \\
\text { tempelkan pada bagian } \\
\text { yang terkena bisul. }\end{array}$ \\
\hline 2. & 2 & Cabi/Sili & $\begin{array}{l}\text { Diambil beberapa } \\
\text { helai daun lombok }\end{array}$ & $\begin{array}{l}\text { Untuk sakit gigi: diambil } \\
\text { beberapa helai daun } \\
\text { lombok, dicuci kemudian } \\
\text { di haluskan dan di tempel } \\
\text { pada bagian pipi dekat } \\
\text { gigi yang sakit. }\end{array}$ \\
\hline
\end{tabular}




\begin{tabular}{|c|c|c|c|c|}
\hline 3. & 3 & Cabi/Sili & $\begin{array}{l}\text { Diambil beberapa } \\
\text { helai daun lombok }\end{array}$ & $\begin{array}{l}\text { - Untuk sakit gigi: diambil } \\
\text { beberapa helai daun } \\
\text { lombok, dicuci kemudian } \\
\text { di haluskan dan di tempel } \\
\text { pada bagian pipi dekat } \\
\text { gigi yang sakit. }\end{array}$ \\
\hline
\end{tabular}

Saat ini, masyarakat Desa Waiwuring masih mempercayai pengobatan tradisional. Selain dipercaya mampu menyembuhkan penyakit dengan cepat, perolehan tumbuhan obat juga sangat mudah di temukan. Masyarakat yang sakit, tidak jarang untuk berobat ke tabib/dukun setempat atau ke pusat kesehatan desa. Pemanfaatan tumbuhan obat ini juga di tanyakan oleh masyarakat setempat tentang cara penggunaan tumbuhan obat yang mampu menyembuhkan penyakit kepada tabib/dukun (Tabel 1). Pengetahuan yang diberikan disesuaikan dengan tinggat pengalaman akan suatu tanaman yang ebrkhasiat sebagai obat (Bare dkk. 2021; Bare dan Sari 2021). Pengobatan tradisional ini menjadi salah satu pilihan pertama masyarakat untuk mengobati suatu penyakit akibat kerbatasan ekonomi. Pengobatan tradisional ini selain digunakan untuk pertolongan pertama, penggunaan bahan yang dijadikan sebagai obat tradisional mudah diperoleh (Astria 2007).

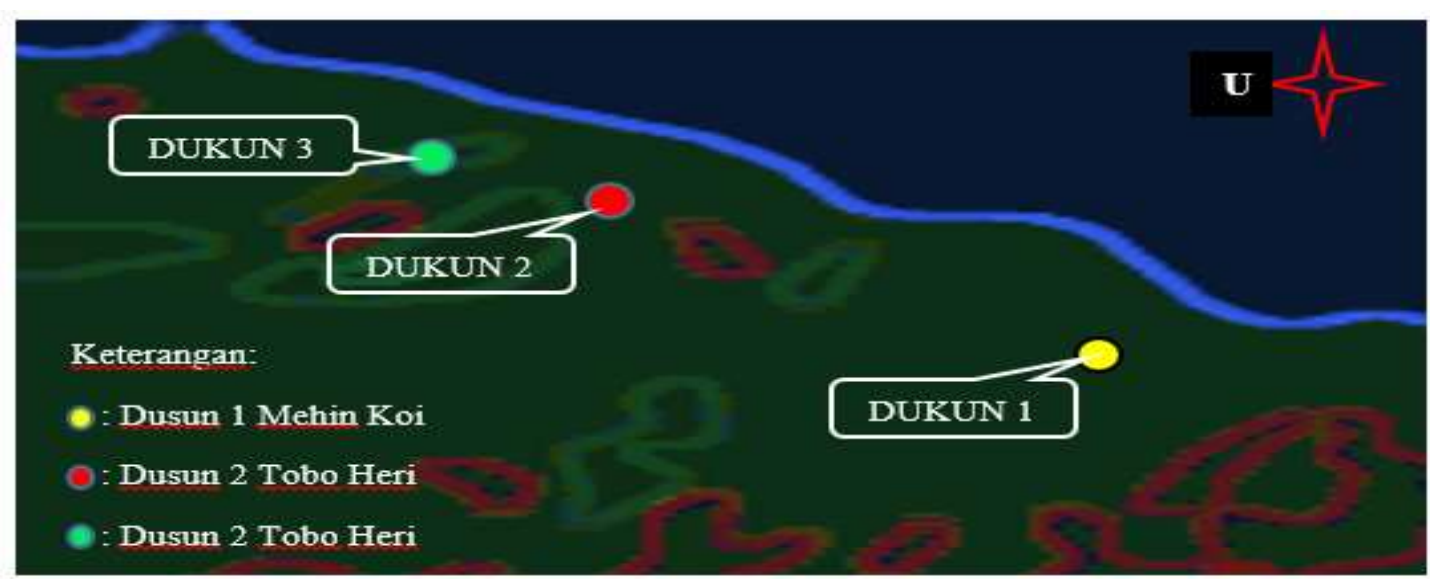

Gambar 2. Peta Pola Persebaran Tabib/Dukun Desa Waiwuring

Desa Waiwuring memiliki 3 dusun, diantaranya:

1) Dusun 1 Mehin Koi

Berdasarkan hasil wawancara dukun 1 kakek Amir (75) tamatan sekolah menengah pertama, beliau memulai praktek mengobati sejak berumur 26 tahun. Penyakit yang sering di obati diantaranya sakit gigi, bisul, sakit kepala, serampa, 
dan beberapa penyakit lainnya. Untuk pengobatan sakit gigi dan bisul, kakek Amir menggunakan beberapa organ dari tanaman cabai seperti daun cabai dan biji cabai. Pengobatan sakit gigi beliau menggunakan biji cabai yang diambil kemudian dibakar, lalu di asapkan menggunakan bambu yang berukuran sangat kecil. Setelah itu, asap cabai yang berada di dalam bambu di tampung pada kapas, kemudian dari kapas tersebut di masukkan ke bagian gigi yang sakit (berlubang). Sementara itu, pengobatan bisul menggunakan daun cabai dengan cara diambil beberapa helai daun, dicuci bersih, kemudian dihaluskan lalu di tempelkan pada bagian yang sakit.

2) Dusun 2 Tobo Heri

Dukun 2 yaitu kakek Tamrin (69) tamatan sekolah dasar. Beliau memulai praktek mengobati sejak tahun 1989. Beberapa penyakit yang sering di obati yaitu demam, sakit gigi, serampa, dan penyakit lainnya. Penobatan sakit gigi, biasanya kakek Tamrin menggunakan beberapa helai daun cabai merah keriting, dicuci, kemudian dihaluskan dan di tempel pada bagian pipi dekat gigi yang sakit. Proses pengobatan ini selama 3 hari sampai sembuh.

3) Dusun 2 Tobo Heri

Sesepuh yaitu kakek Abdul (68) tamatan sarjana pendidikan. Beliau tidak spesifik mengobati masyarakat seperti halnya dukun dalam mengobati, hanya saja kakek Abdul mengobati masyarakat apabila dalam keadaan mendesak (dukun yang sering mengobati sedang tidak ada di kampung atau sedang pergi bekerja). Kemampuan mengobati yang dimiliki kakek Abdul adalah turun temurun. Organ tanaman cabai yang digunakan dalam mengobati adalah daun cabai yang diambil, kemudian dicuci bersih dan di haluskan. Setelah itu, daun yang telah dihaluskan tersebut di tempelkan pada bagian pipi dekat gigi yang sakit. Proses pengobatan dapat berlangsung selama 3 sampai 4 hari sampai sembuh.

Hasil wawancara tabib/dukun dan sesepuh kampung tersebut dapat disimpulkan bahwa bagian tanaman yang dijadikan obat adalah bagian daun dan biji cabai untuk mengobati sakit gigi dan bisul. Dengan cara diambil beberapa helai daun, dicuci, kemudian di haluskan lalu ditempel pada bagian yang sakit. Sementara itu, untuk biji cabai diambil bijinya, kemudian dibakar, lalu di asapkan menggunakan bambu yang berukuran sangat kecil. Setelah itu, asap cabai yang berada di dalam bambu di tiup dan di tampung pada kapas, kemudian dari kapas tersebut di masukkan dibagian gigi yang sakit (berlubang). 
Pemanfaatan tanaman cabai sebagai obat sesuai dengan penelitian Syafriadi dkk., (2017); Slamet dan Andarias, (2018), yang mengatakan bahwa cabai merah keriting (Capsicum annum L.) biasa digunakan sebagai bahan masakan, selain itu juga dapatdimanfaatkan sebagai obat penurun demam pada anak dan obat sakit gigi. Cara pengolahannya untuk menurunkan demam pada anak adalah, dengan mengambil daun cabai merah keriting secukupnya lalu dihaluskan, kemudian tambahkan santan kelapasecukupnya, aduk rata, dan oleskan keseluruh badan anak yang demam. Sementara itu, untuk mengobati sakit gigi dengan cara diambil dua helai daun cabai, kemudian dicuci bersih lalu di kunyah.

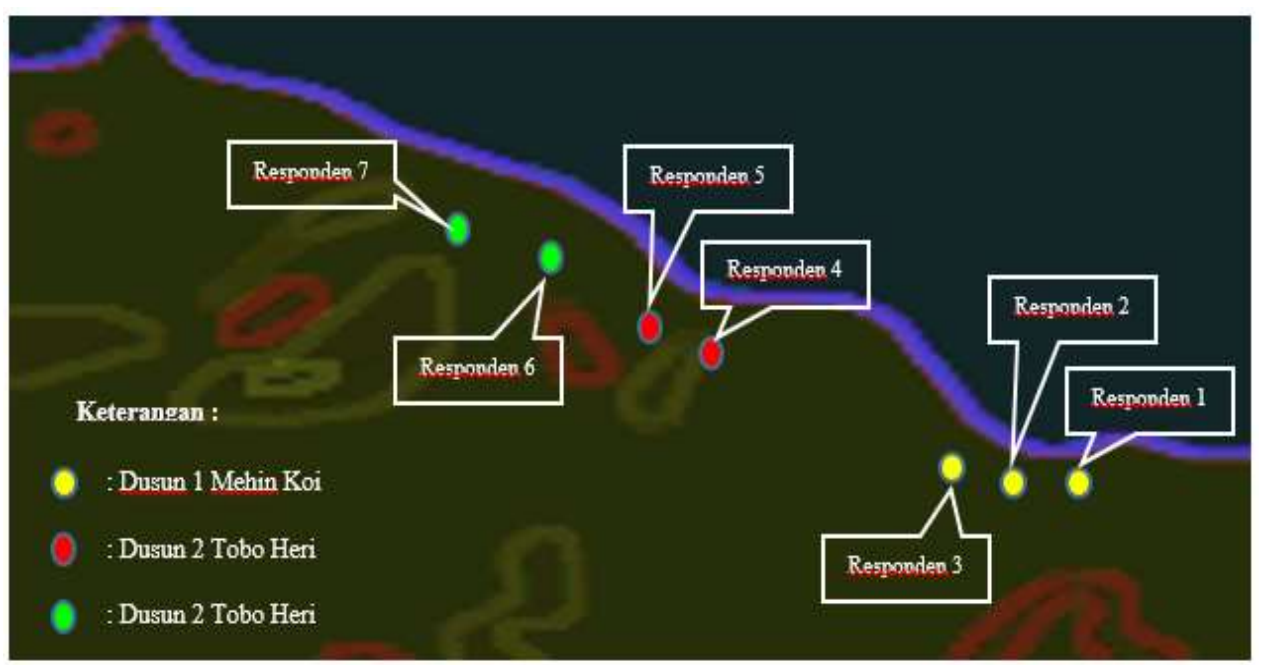

Gambar 3. Peta pola penyebaran responden Desa Waiwuring

Berdasarkan wawancara masyarakat desa Waiwuring dengan 10 responden diantaranya 3 informan kunci (key informan) dan 7 orang informan non-kunci, menyatakan bahwa cabai merah keriting (Capsicum annum L.) umumnya dimanfaatkan oleh tabib/dukun dan sesepuh kampung sebagai obat tradisional yang dipercaya mampu menyembuhkan penyakit seperti bisul dan sakit gigi. Bagian tumbuhan yang digunakan dalam pengobatan sakit gigi dan bisul adalah daun cabai merah keriting, selain itu biji cabai merah keriting juga digunakan untuk mengobati sakit gigi.

Tabel 2. Nama-nama responden Desa Waiwuring

\begin{tabular}{|c|c|c|}
\hline No. & Nama Responden & Hubungan Dengan Dukun \\
\hline 1. & A.A & Pasien Dukun 1 \\
\hline 2. & F.B.T & Pasien Dukun 1 \\
\hline 3. & S.H & Pasien Dukun 1 \\
\hline 4. & M.C & Pasien Dukun 2 \\
\hline 5. & M.H & Pasien Dukun 2 \\
\hline
\end{tabular}




\begin{tabular}{lll}
\hline 6. & S.B & Pasien Dukun 3 \\
7. & H.S.B & Pasien Dukun 3 \\
\hline
\end{tabular}

Pemanfaatan bagian daun dari tanaman obat ini adalah salah satu upaya konservasi terhadap tumbuhan obat. Penggunaan daun sebagai obat tidak berdampak buruk bagi kelangsungan hidup tumbuhan. Pada daun banyak terakumulasi senyawa metabolit sekunder yang berguna sebagai obat yaitu tanin, alkaloid, minyak atsiri dan senyawa organik lainnya (Mulyani dkk., 2020). Pengetahuan masyarakat harus dilestarikan agar dapat wariskan kepada generasi berikut.

\section{SIMPULAN}

Pemanfaatan jenis tumbuhan cabai mera keriting (Capsicum annum L.) di Desa Waiwuring, Kecamatan Witihama, Kabupaten Flores Timur, selain digunakan sebagai bumbu dapur dapat juga digunakan sebagai obat tradisional. Beberapa cara pengolahan sebagai obat diantaranya diambil beberapa helai daun cabai merah keriting, dicuci, dihaluskan dan kemudian ditempelkan pada bagian yang terkena bisul. Sedangkan untuk pengobatan sakit gigi dengan cara diambil biji cabai merah keriting, kemudian dibakar, lalu di uapkan menggunakan bambu yang berukuran sangat kecil. Setelah itu, asap cabai yang berada di dalam bambu di tiup dan di saring menggunakankapas, kemudian dari kapas tersebut di simpan dibagian gigi yang sakit (berlubang).

\section{DAFTAR PUSTAKA}

Astria. 2007. "KAJIAN ETNOBOTANI TUMBUHAN OBAT PADA MASYARAKAT DUSUN SEMONCOL KECAMATAN BALAI KABUPATEN SANGGAU."

Bare, Yohanes et al. 2019. "Prediction Potential Chlorogenic Acid As Inhibitor Ace (In Silico Study)." Bioscience 3(2): 197.

2021. "ANALISIS SENYAWA FITOSTEROL Cymbopogon citratus dan Curcuma longa SEBAGAI ANTIALZHEIMER." Biopendix: Jurnal Biologi, Pendidikan dan terapan 7(2): 53-159.

2021. "Implementasi Biology Club I Di SMA Karitas Watuneso, Kecamatan Lio Timur, Kabupaten Ende." Jurnal ABDINUS : Jurnal Pengabdian Nusantara 4(2): $321-28$.

Bare, Yohanes, Maria Helvina, Gabriella Chandrakirana Krisnamurti, and Mansur S. 2020. "The Potential Role of 6-Gingerol and 6-Shogaol as ACE Inhibitors in Silico Study.” Biogenesis: Jurnal Ilmiah Biologi 8(2): 210.

Bare, Yohanes, and Dewi Ratih Tirto Sari. 2021. "Pengembangan Lembar Kerja Mahasiswa (LKM) Berbasis Inkuiri Pada Materi Interaksi Molekuler.” BioEdUIN 11(1): 8 .

Bhadoriya, Santosh Singh. 2012. "Anti-Inflammatory and Antinociceptive Activities of a Hydroethanolic Extract of Tamarindus Indica Leaves." Scientia Pharmaceutica 80(3): 685-700.

BPS, Data Kabupaten FLOTIM. 2013. "Profil Daerah Kabupaten Flores Timur.” 
Fitriani, Latifah, Toekidjo, and Setyastuti Purwanti. 2013. "Keragaman Lima Kultivar Cabai (Capsicum Annum L.) Di Dataran Medium.” Vegetalika 2 No.2, 2013 : 5063.

Izzati, Fauzia. 2018. "Capsaicinoids dari Capsicum spp. Dan Penggunaannya Sebagai Riot Control Agent." BioTrends 9 No.2 Tahun 2018: 9.

Mulyani, Yani, Patonah Hasimun, and Rendi Sumarna. 2020. "Kajian Etnofarmakologi Pemanfaatan Tanaman Obat Oleh Masyarakat Di Kecamatan Dawuan Kabupaten Subang Provinsi Jawa Barat: Ethnopharmacology Study of utilization medicinal plant by Society in Dawuan sub-district Subang Regency West Java Province." Jurnal Farmasi Galenika (Galenika Journal of Pharmacy) (e-Journal) 6(1): 3754.

Slamet, Agus, and S Hafidhawati Andarias. 2018. "Studi Etnobotani dan Identifikasi Tumbuhan Berkhasiat Obat Masyarakat Sub Etnis Wolio Kota Baubau Sulawesi Tenggara." : 12.

Syafriadi, A, Aisyah R Nasution, and Mahdalena. 2017. "KAJIAN ETNOBOTANI MELALUI PEMANFAATAN TANAMAN OBAT DI DESA REMA KECAMATAN BUKIT TUSAM KABUPATEN ACEH TENGGARA." Prosiding Seminar Nasional Biotik. 